uncommonly readable. I would question, however, the interpretation of the observation that androgen production of the retained testis is reduced below normal levels in spontaneous cryptorchidism. This is presented as evidence that increased temperature impairs androgen production and this evidence is regarded as being opposed to evidence based on experimental cryptorchidism. Surely the situation in the natural cryptorchid is such that it is difficult to separate cause and effect.

The final chapter, "Fine structure of the testis and its functional significance" by M. H. Burgos, R. Vitale-Calpe and A. Aoki, is concerned much more with fine structure than with functional significance, but it combines a valuable text with a very beautiful atlas of the ultrastructural features of the cytological components of the testis. There are one or two minor distractions in the text such as the use of "human" as a noun and the remark (p. 561) that "figure 38 shows a very suggestive picture". And I found the description of the limiting membrane (p. 553) difficult to interpret; my difficulties were resolved when I realized that the sentence "the inner lamella contacts the cells of the tubule which in turn is made up of three layers" does not in fact mean what it says.

In conclusion I have to say that I know that I shall return to this book and I shall certainly direct others to it. It deserves the success which I am sure that it will have.

J. C. HanCOCK

\section{Drug Resistant Bacteria}

Transferable Drug Resistance Factor $R$. Edited by Susumu Mitsuhashi. Pp. $\mathrm{x}+203$. (University Park: Baltimore, London and Tokyo, December 1970.) $\$ 14.50$.

ONE of the most interesting bacteriological discoveries of recent years has been that of transferable drug resistance and Dr Mitsuhashi was prominent among those people who studied the phenomenon earliest and most intensively. A book from him is therefore of particular value. For several years, work on transferable drug resistance was confined to Japan, and many of the findings were published in Japanese journals, where they were not accessible to the large number of microbiologists of other nationalities who have since become interested. Mitsuhashi's book, which contains details of much of the early Japanese work, will be especially appreciated on this account. As well as editor, Mitsuhashi is author, or coauthor, of every chapter of the book, giving it a unity of approach. The English may be faulty in places, but never to the point where it obscures the meaning.
$R$ factors responsible for transferable drug resistance belong to the group of genetic elements known as bacterial plasmids which exist separately from the bacterial chromosome, but whose replication is more or less tightly coordinated with it, depending on the individual plasmid and on the species of host. "Transferable" is used here to mean transfer by conjugation, and transferability is conferred by a set of genes known as the sex factor of the same general nature as those in the $F$ sex factor responsible for genetic recombination in Escherichia coli $\mathrm{K} 12$. Antibiotic resistance is conferred by genes which, in those cases where their action is understood, determine the production of enzymes destroying the activity of the antibiotic molecule.

The first chapter of Mitsuhashi's book is a history of the evolution of drug resistance amongst bacteria, chiefly Shigellae, in Japan and the emergence about 1957 of strains which had developed resistance to three or four drugs in a way that could not be reconciled with the process of repeated mutations and selection generally acceptable at the time. This introduction leads into an account of the discovery of $R$ factors and of the prevalence and geographical distribution of different combinations of resistances, which is further developed in chapter 2 . $R$ factors can be transmitted to, and maintained by, many Gram-negative species, although with vastly differing efficiency.

A chapter with Dr Harada deals with the physiology of transfer, the structure of the $R$ factor DNA molecule, control of its replication, and superinfection immunity. The chapter on genetics, with Dr Hashimoto, includes the resistance characters as well as those concerned with replication and transfer, and contains much detail of individual factors. The ability of $R$ factors to coexist with $F$ has made complementation studies possible, and the inability of two similar $R$ factors to coexist has facilitated selection of recombinants. The other methods of genetic analysis described involve transduction by phage, analysis of plasmid segregation patterns, and recombination or complementation between segregants having point mutations in their resistance genes.

Dr Sawai is joint author of the chapter on biochemical mechanisms of the resistances conferred by $R$ factors, which are remarkable in differing from drug-resistance acquired by chromosomal mutation. These mechanisms have done little, so far, to reveal the origin of $R$ factors-the subject of the last chapter of the book. The most commionly found $\boldsymbol{R}$ factor-determined $\beta$-lactamase is similar in its properties to an enzyme often produced by
Klebsiella strains, and chloramphenicol acetylase like that determined by $R$ factors has been found in various enterobacteria and in staphylococci. Nevertheless, these are no more than possible indications because there is, as yet, no firm evidence that the enzymes here are not still the products of plasmid genes. ELINOR MEYNELL

\section{Reptiles Completed}

Traité de Zoologie : Anatomie, Systématique, Biologie. Publié sous la direction de Pierre P. Grassé. Tome XIV: Reptiles-Glandes Endocrines-Embryologie - Systématique - Paléontologie (Fascicule III). Pp. 681-1428. (Masson: Paris, 1970.) 240 francs.

THIs volume completes the survey of reptiles in the Traité.

There are splendid chapters on the endocrine organs variously written by Saint-Girons, Gabe and Martoja. As a systematist I am tremendously grateful to such specialists, using the latest histochemical techniques, who have done so much more than obtain some specimens from a local dealer and then make pronouncements on reptiles. They have acquainted themselves with the problems of reptile systematics and have gone to much trouble to obtain a wide selection of material. At the end of a generously illustrated technical account they discuss the bearing which they consider their findings to have on reptilian systematics. The systematist who would use all available evidence has too often to wade through technical accounts of matters with which he has had no contact above undergraduate level, if that, and hope that he is extracting the significant information.

There are chapters by Guibe on the urinogenital system, reproduction, autotomy and regeneration, ecology and population dynamics. The reproduction and ecology chapters review much recent and interesting work and the survey of population dynamics is a welcome innovation. Matthey has a good review of reptilian chromosomes, an area which is now growing fast. Grassé considers the present state of knowledge of parthenogenesis in reptiles, a new and unexpected development. In an important chapter on development Pasteels draws together a wealth of scattered information. $\mathrm{He}$ gives an account of the descriptive and experimental analysis of early development as far as it is known and follows with an outline of organogeny. Pasteels generalizes as far as the fragmentary information permits and at the same time clearly indicates the major lacunae in our knowledge.

Unfortunately substandard is the chapter on geographical distribution, 